\title{
HOMOGENIZATION OF PARTICLE SIZES IN LaTiO 2 N OXYNITRIDE PIGMENTS BY BEAD-MILLING TECHNIQUE
}

\author{
KAORU SHINNOU, HIRONORI FUJITO, TOMOOKI KAWASAKI, HIDEHITO ANDO, \\ MAIKO MITO, KEI-ICHIRO MURAI and TOSHIHIRO MORIGA* \\ Department of Chemical Science and Technology, Graduate School of Advanced Technology and Science, \\ The University of Tokushima 770-8506, Japan \\ "moriga@chem.tokushima-u.ac.jp
}

\begin{abstract}
Diffuse reflectivity in the longer wavelength region after the absorption edge was studied on the $\mathrm{LaTiO}_{2} \mathrm{~N}$ nitrided. It was discussed in the viewpoint of particle sizes by use of ball milling and bead milling technique. The diffuse reflectivity after absorption edge of the $\mathrm{LaTiO}_{2} \mathrm{~N}$ powders got lower in accordance with the reduction of particle sizes. In case of $\mathrm{LaTiO}_{2} \mathrm{~N}$ aqueous suspension after the beadmilling treatment in which the primary particles were well dispersed, remarkable enhancement of the diffuse reflectivity was observed with decreasing the average particle sizes.
\end{abstract}

Keywords: Oxynitride; ball-milling; bead-milling, particle size, suspension.

\section{Introduction}

Perovskite-type $\mathrm{LaTiO}_{2} \mathrm{~N}$ oxynitrides are promising materials with band gap in visiblelight area as non-toxic inorganic pigment $[1,2]$. In $\mathrm{LaTiO}_{2} \mathrm{~N}$, the optical band gap varied through the control of $\mathrm{O} / \mathrm{N}$ ratio and the diffuse reflectivity in the longer wavelength region after the absorption edge varied through the control of $\mathrm{Ti} / \mathrm{La}$ ratio $[3,4,5]$. It has not been clarified in the past studies why the diffuse reflectivity deteriorated as $\mathrm{Ti} / \mathrm{La}$ ratio increased. At first, the deterioration of the reflectivity may result from the formation of lower-valence such as colored $\mathrm{Ti}^{3+}$. However, XPS measurement revealed that such a kind of cation nonstoichiometry did not affect the valence state [5]. As observed in the SEM images, there was a progression of the aggregation of the primary particles with an increase of $\mathrm{Ti} / \mathrm{La}$ ratio [6]. We considered that the particle configuration should affect on the reflectivity. In this study, we tried to pulverize $\mathrm{LaTiO}_{2} \mathrm{~N}$ oxynitride powders by the mechanical ball milling method and the bead milling technique to investigate the relation between the degradation of diffuse reflectivity and the particle size. $\mathrm{LaTiO}_{2} \mathrm{~N}$ aqueous suspension was formed by bead milling technique to suppress re-aggregation of the dispersed particles.

\section{Experimental}

Preparation of samples: $\mathrm{LaTiO}_{2} \mathrm{~N}$ was prepared by heating the oxide precursor under a $\mathrm{NH}_{3}$ gas flow. The metal-oxide precursor was prepared by the polymerized complex 
method. The practical preparation of the oxide precursor and nitridation to $\mathrm{LaTiO}_{2} \mathrm{~N}$, was followed with the reference [5].

Ball milling treatment of the sample: The milling treatment was conducted with the planet type ball mill, Fritsch P-7, Germany. The sample and balls with about 15 times in weight was put in a container. Ethanol was added until they were fully soaked and the milling was conducted. The balls $(5 \mathrm{~mm} \phi)$ and container were made of zirconia. The samples after finishing ball milling treatment were fully dried to remove ethanol at 110 ${ }^{\circ} \mathrm{C}$ by dry oven.

Bead milling treatment of sample: The milling treatments was conducted with the strong shaker (SR-2DS) of Titec Co.,Ltd.. The sample and distilled water with about 18 times, beads with 10 times in weight was put in a plastic container. As a dispersing agent, DISPERBYK-190 (BYK-Chmie Japan Co., Ltd.) was added. The beads $(0.5 \mathrm{~mm} \phi)$ were made of zirconia-yttria. The samples after finishing bead milling treatment were fully dried to remove distilled water at $110^{\circ} \mathrm{C}$ by dry oven.

Measurements and treatments: The cation ratio of oxynitride was determined by Inductively Coupled Plasma-Atomic Emission Spectroscopy (ICP-AES) (Seiko Instruments SPS1500VR). Oxynitride for the ICP measurement were dissolved in nitric acid, and diluted by distilled water in order to obtain the appropriate concentration for the measurement. Phase identification and lattice constant determination were performed by powder X-ray diffractometry (Rigaku RINT-2500VHF+) using monochromatized CuK $\alpha$ radiation with a source power of $40 \mathrm{kV}$ and $150 \mathrm{~mA}$. Optical diffuse reflectance spectra were measured with a double beam spectrometer (JASCO V-670DS). A PTFE (Polytetrafluoroethylene) compact was used a reference. Diffuse reflectance spectra of samples were analogous to transmission spectra of thin-film samples. Scanning Electronic Microscope (SEM) images by a Hitachi S-4700 were collected with the conditions of an acceleration voltage of $3 \mathrm{kV}$ and an emission current of $10 \times 10^{-6} \mathrm{~A}$. The measurement of particle size distribution was conducted by micro track particle size distribution counter Nikkiso X-100 based on laser diffraction and scattering method. $0.014 \mathrm{~g}$ of sodium hexa-metaphosphate as a dispersoid was solved in $7 \mathrm{~g}$ of distilled water as a disperse medium. Then $0.02 \mathrm{~g}$ of sample was added into the solution and ultrasonic-treatment was applied for a minute to be dispersed homogeneously in the solution.

\section{Results and Discussion}

\subsection{The diffuse reflectivity and light absorption of $\mathrm{LaTiO}_{2} \mathrm{~N}$ nitridation}

Figure 1 shows the relationship among diffuse reflectivity in the longer wavelength region after the absorption edge, the primary particle size against $\mathrm{Ti} / \mathrm{La}$ ratio. The edges lay invariant at around $600 \mathrm{~nm}$ as they had the almost same $\mathrm{O} / \mathrm{N}$ ratio $[4,6]$. The reflectivity at $650 \mathrm{~nm}$ for the ball-milled oxynitrides lowered with increasing $\mathrm{Ti} / \mathrm{La}$ ratio, whereas the primary particle size after the milling was almost constant. This result depicted that the particle size did not seem to contribute to the degradation of diffuse reflectivity, contrary to the consideration from the SEM images. 


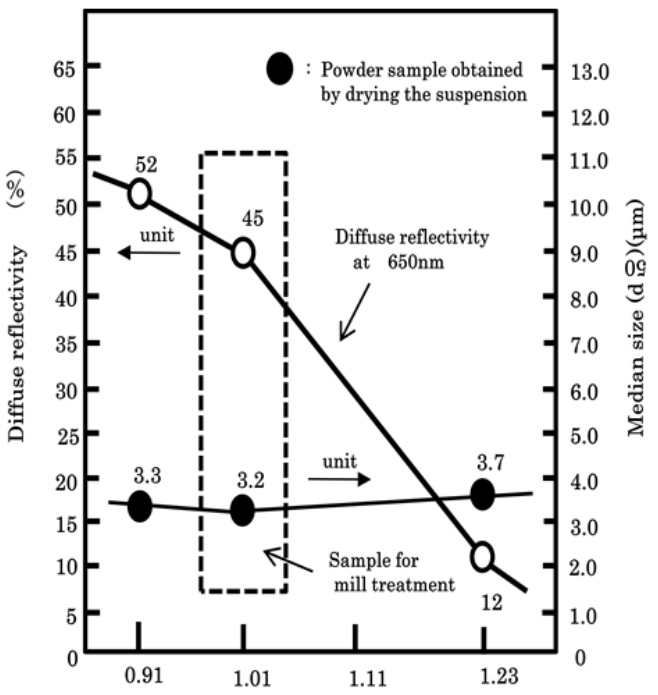

Fig.1 Relation among diffuse reflectivity and the primary particle size against $\mathrm{Ti} / \mathrm{La}$ ratio after nitridation

\subsection{The property of the powder sample by ball mill}

Table 1 shows the median size and anion ratio of $\mathrm{LaTiO}_{2} \mathrm{~N}$ powder applied the ball milling treatment. The particle size shrank with treatment time of ball milling until $5 \mathrm{~h}$, and in case of $10 \mathrm{~h}$, the average particle size became larger, maybe resulting from re-aggregation. As seen table 1, the samples with the milling after nitridation gradually increased in $\mathrm{O} / \mathrm{N}$ ratio with increasing the milling duration time. The longer milling duration enhanced the nitrogen elimination of oxynitride powders in the process of splitting off the powders mechanically.

Table 1. Median size and anion $\mathrm{O} / \mathrm{N}$ ratio of ball-milled $\mathrm{LaTiO}_{2} \mathrm{~N}$ powder $(\mathrm{Ti} / \mathrm{La}=1.01)$

\begin{tabular}{|c|c|c|}
\hline Time of ball milling & Average particle & O/N ratio \\
\hline $0 \mathrm{~h}$ & $1.896 \mu \mathrm{m}$ & 2.7 \\
\hline $3 \mathrm{~h}$ & $0.375 \mu \mathrm{m}$ & 3.8 \\
\hline $5 \mathrm{~h}$ & $0.261 \mu \mathrm{m}$ & 3.8 \\
\hline $10 \mathrm{~h}$ & $0.433 \mu \mathrm{m}$ & 4.4 \\
\hline
\end{tabular}

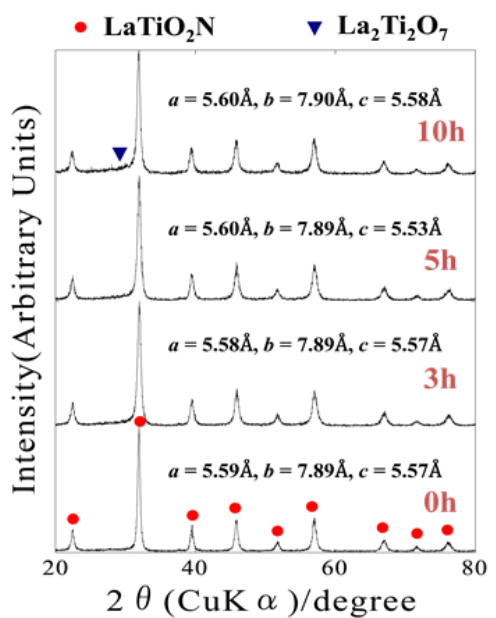

Fig.2 XRD patterns of ball-milled $\mathrm{LaTiO}_{2} \mathrm{~N}$ powder $(\mathrm{Ti} / \mathrm{La}=1.01)$

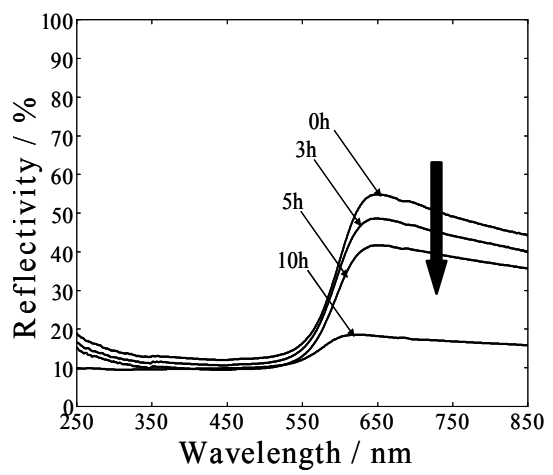

Fig.3 Diffuse reflectance spectra of ball-milled $\quad \mathrm{LaTiO}_{2} \mathrm{~N}$ powder $(\mathrm{Ti} / \mathrm{La}=1.01)$. 
Figure 2 shows the XRD patterns of ball-milled $\mathrm{LaTiO}_{2} \mathrm{~N}$ powder $(\mathrm{Ti} / \mathrm{La}=1.01)$ for $0 \mathrm{~h}, 3 \mathrm{~h}, 5 \mathrm{~h}, 10 \mathrm{~h}$, respectively. The samples except $10 \mathrm{~h}$ ball-milled sample kept a single phase of perovskite-type structure and the poor-crystalline phase of $\mathrm{La}_{2} \mathrm{Ti}_{2} \mathrm{O}_{7}$ was slightly seen in the $10 \mathrm{~h}$ sample. Figure 3 shows the degradation trend of diffuse reflectivity in the region after absorption edge with an increase of ball milling duration time. This reason could be explained as following. The light scattering on the particle surface increases with a reduction of the particle size. However, the light absorption by a large number of densely-packed particles also increases at the same time. These two phenomena counteracted each other, but the absorption behavior might be dominant, so that the reflectivity in the longer wavelength region after the absorption edge lowered.

\subsection{The property of powder sample by bead mill}

Table 2. Median size and anion $\mathrm{O} / \mathrm{N}$ ratio of bead-milled $\mathrm{LaTiO}_{2} \mathrm{~N}$ powder and suspension $(\mathrm{Ti} / \mathrm{La}=1.01)$

\begin{tabular}{|c|c|c|c|}
\hline \multirow{2}{*}{ Time of bead mill } & \multicolumn{2}{|c|}{ Average particle size $(\mathrm{d} 50)(\mu \mathrm{m})$} & \multirow{2}{*}{$\begin{array}{c}\text { O/N ratio } \\
\text { (powder sample) }\end{array}$} \\
\cline { 2 - 3 } & Powder sample & Aqueous suspension & 3.4 \\
\hline $0 \mathrm{~h}$ & 3.162 & 6.670 & 3.3 \\
\hline $4 \mathrm{~h}$ & 0.384 & 0.301 & 3.5 \\
\hline $8 \mathrm{~h}$ & 0.331 & 0.216 & 3.4 \\
\hline $24 \mathrm{~h}$ & 0.187 & 0.170 & \\
\hline
\end{tabular}
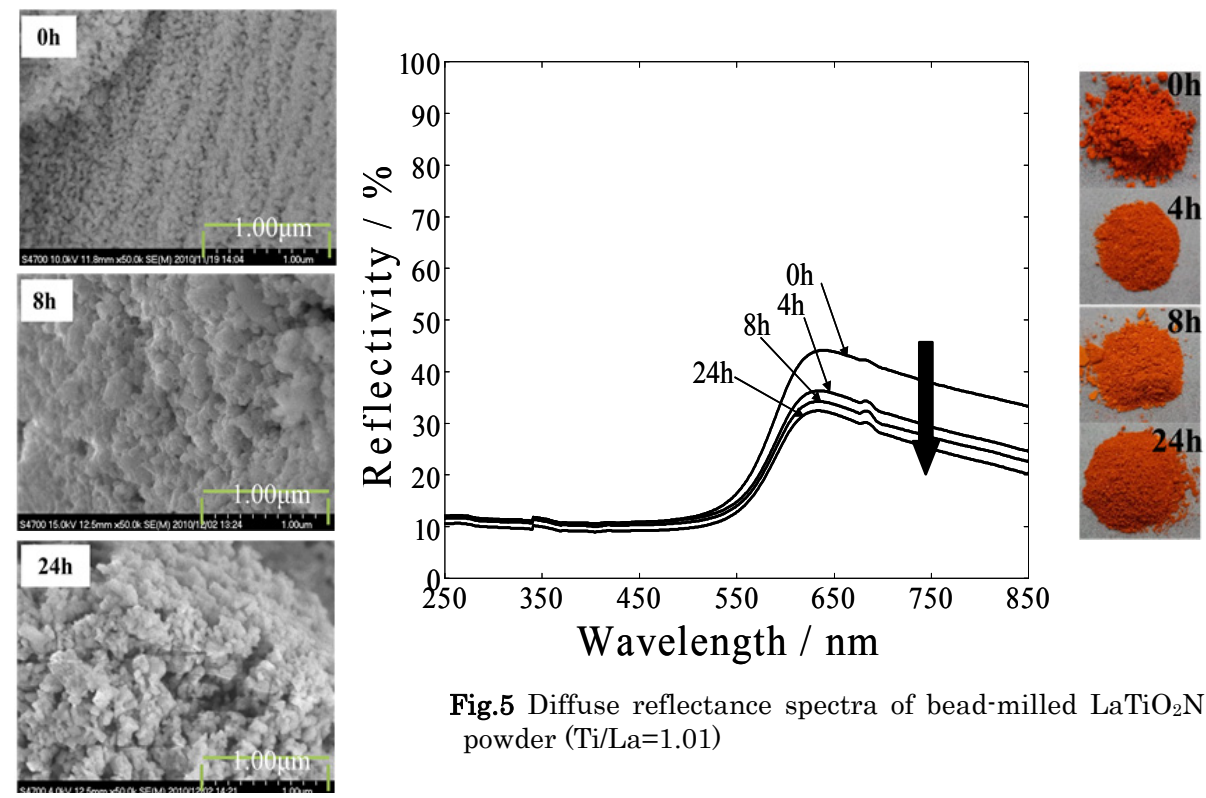

Fig.5 Diffuse reflectance spectra of bead-milled $\mathrm{LaTiO}_{2} \mathrm{~N}$ powder $(\mathrm{Ti} / \mathrm{La}=1.01)$

Fig. 4 SEM images of bead-milled $\mathrm{LaTiO}_{2} \mathrm{~N}$ powder $(\mathrm{Ti} / \mathrm{La}=1.01)$ 
Table 2 showed median size and anion $\mathrm{O} / \mathrm{N}$ ratio of bead-milled $\mathrm{LaTiO}_{2} \mathrm{~N}$ powder and suspension. The particle size became smaller with the treatment time until $24 \mathrm{~h}$ and the ground speed by bead-milling was more slowly than that by ball-milling. Figure 4 shows SEM images of bead-milled $\mathrm{LaTiO}_{2} \mathrm{~N}$ powder. From these images, the aggregation was observed as well as ball milling. As seen in table 2, the samples with the milling were nearly constant in $\mathrm{O} / \mathrm{N}$ ratio with increasing the milling duration time. The nitrogen elimination from the oxynitrides was prevented because the bead milling weakly grinds particles by bringing low pressure. Figure 5 shows the degradation trend of diffuse reflectivity in the longer wavelength region after the absorption edge with increase of bead milling duration time. It can be seen that the degradation of diffuse reflectivity for the $10 \mathrm{~h}$ ball-milled sample was lower as compared with the $24 \mathrm{~h}$ bead-milled sample. It can be estimated that the remarkable degradation of diffuse reflectivity for the $10 \mathrm{~h}$ ballmilled sample is due to light absorption by defects probably introduced to the particles by the nitrogen elimination during ball milling.

\subsection{The property of aqueous suspension by bead mill}

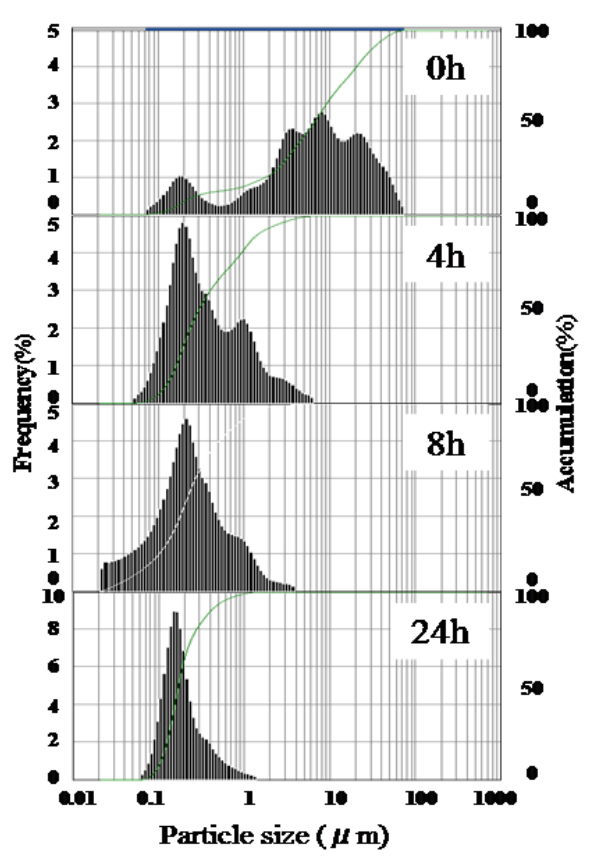

Fig.6 Particle size distribution of bead-milled $\mathrm{LaTiO}_{2} \mathrm{~N}$ dispersion (Ti/La=1.01).
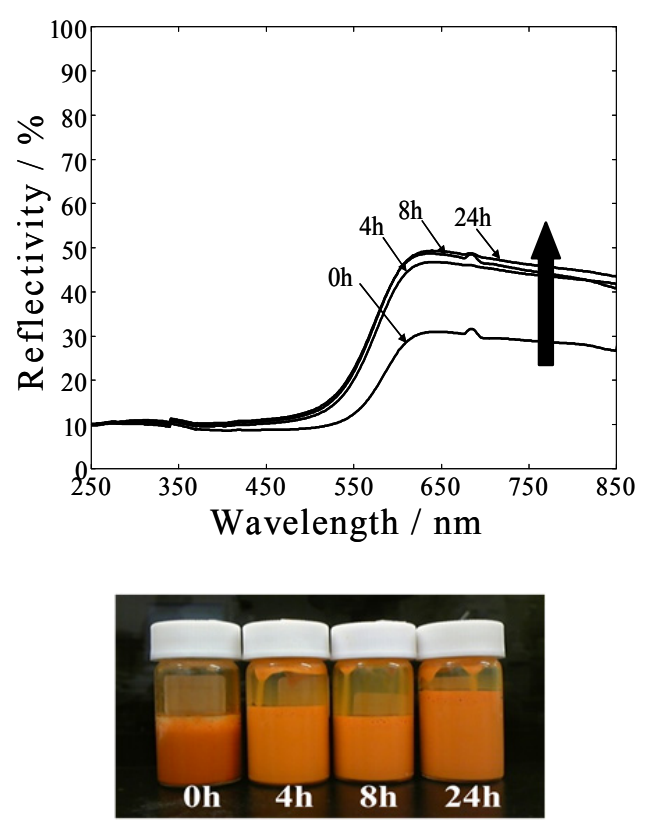

Fig.7 Diffuse reflectance spectra of bead-milled $\mathrm{LaTiO}_{2} \mathrm{~N}$ dispersion (Ti/La=1.01). 
Figure 6 shows the particle size distribution of $\mathrm{LaTiO}_{2} \mathrm{~N}$ in aqueous suspension with varying treatment time by bead milling for $4 \mathrm{~h}, 8 \mathrm{~h}$, and $24 \mathrm{~h}$, respectively. It can be seen that the particle size distribution of $\mathrm{LaTiO}_{2} \mathrm{~N}$ in aqueous suspension by the bead milling, was sharp. As shown in table 2, the particle size shrank with the treatment time until $24 \mathrm{~h}$ and the measured particle size distribution without the bead milling showed almost same size as compared with the particle size obtained by drying the suspension. Sharp particle size distribution at around $100 \mathrm{~nm}$ in the $\mathrm{LaTiO}_{2} \mathrm{~N}$ in aqueous suspension could be achieved for the $24 \mathrm{~h}$ bead-milled sample. Figure 7 showed the remarkable enhancement of diffuse reflectivity in the region after absorption edge with increase of bead milling duration time in such a re-aggregation-free suspension. This reason could be explained as following. The particle density of powders in the suspension is extremely low in comparison to the powdery $\mathrm{LaTiO}_{2} \mathrm{~N}$ oxynitride compact, resulting in reducing a light absorption by the particles. It is presumable that wide, broad interspaces among particles in the suspension cause an increase of transmission of reflected lights to enhance the observed reflectivity.

\section{Conclusion}

We have tried to investigate reasons of the degradation of diffuse reflectivity in the region after absorption edge of the $\mathrm{LaTiO}_{2} \mathrm{~N}$ powders by use of ball mill and bead mill techniques. The degradation of the diffuse reflectivity in the region after absorption edge of the $\mathrm{LaTiO}_{2} \mathrm{~N}$ powders in accordance with the reduction of particle sizes would be due to an increase of the light absorption by a large number of densely-packed particles. In case of $\mathrm{LaTiO}_{2} \mathrm{~N}$ aqueous suspension after the bead-milling treatment in which the primary particles were well dispersed, remarkable enhancement of the diffuse reflectivity in the region after absorption edge was observed with a decrease of the average particle size.

\section{Acknowledgments}

This study (Approved Number a09E52007) was supported by Industrial Technology Research Grant Program in 2009 from New Energy and Industrial Technology Development Organization (NEDO) of Japan.

\section{References}

1. Kasahara A, Nukumizu K, Hitoki G, Takata T, Kondo J N, Hara M, Kobayashi H and Domen K 2002 J. phys. Chem. A 1066750

2. Kasahara A, Nukumizu K, Takata T, Kondo J N, Hara M, Kobayashi H, and Domen K $2003 \mathrm{~J}$. phys. Chem. B 1077912002 J. phys. Chem. A 1066750

3. Moriga T, Aoki D, Nishida Y, Kitaji K, Takahara K, Murai K and Nakabayashi I 2006 phys. stat. sol. (a) 2032818

4. Moriga T, Ikeuchi K, Mashima R, Aoki D and Murai K 2007 J Ceram.Soc. Jpn. 115637

5. Masuda Y, Mashima R, Yamada M, Ikeuchi K, Murai, K, Waterhouse G.I.N, Metson J.B and Moriga T 2009 J. Ceram Soc. Jpn. 11776.

6. Masuda Y, Mashima R, Yamada M, Ando H, Kawasaki T, Murai K and Moriga T 2009 Materials Science and Engineering 1012018. 